\title{
Intraoperative Venous Injury
}

National Cancer Institute

\section{Source}

National Cancer Institute. Intraoperative Venous Injury. NCI Thesaurus. Code C78392.

Damage to a vein during a surgical procedure. 